\title{
CINEMA, EDUCAÇÃO E FORMAÇÃO DOCENTE: POSSIBILIDADES E DESENVOLVIMENTO DA CONSCIENTIZAÇÃO DE MUNDO NA PERSPECTIVA FREIREANA
}

\author{
Maurício Fonseca Pontes ${ }^{1}$, Tatiana Pinheiro de Assis Pontes ${ }^{2}$ \\ ${ }^{1}$ Diretor de escola da Secretaria Municipal de Educação de Araçatuba/SP e Professor de História da Secretaria Estadual \\ de Educação de São Paulo. E-mail: mauricio140474@gmail.com \\ ${ }^{2}$ Doutora em Educação pela Universidade Estadual Paulista - UNESP. Professora Adjunta no Departamento de Ciências \\ da Educação (DECED) da Universidade Federal de São João Del-Rei - UFSJ
}

\section{RESUMO}

Este texto propõe o debate sobre a relação entre a educação pela arte e cultura e a formação estética e ética de professores, compreendendo que a sensibilidade do ser humano, potencializada nesse processo, resulta em efeitos substantivos no campo da educação libertadora, que conduz à conscientização do ser humano. Entre os recursos a serem incorporados nesse processo, destacamos o cinema como instrumento de efetivação da educação pela arte e cultura, pois, esse favorece o (auto) conhecimento dos sentimentos e permite a reflexão crítica sobre a realidade. Portanto, o objetivo central exposto consiste em desenvolver um debate sobre a relação entre o uso do cinema e o desenvolvimento da conscientização na formação docente. Defendemos que nessa direção, a formação docente pode contribuir para superar as formas de inculcação de ideologias desumanizantes e conduzir ao desenvolvimento da democracia na e pela a educação. Trata-se de uma pesquisa bibliográfica, pautada na abordagem qualitativa dos dados.

Palavras-chave: Conscientização. Arte e cultura. Formação estética e ética. Cinema. Formação docente.

\section{MOVIE THEATER, EDUCATION AND TEACHER TRAINING: POSSIBILITIES AND DEVELOPMENT OF WORLD AWARENESS IN THE FREIREANA PERSPECTIVE}

\begin{abstract}
This text proposes the debate about the relationship between education through art and culture and the aesthetic and ethical formation of teachers, understanding that the sensibility of the human being, potentiated in this process, results in substantive effects in the field of liberating education, which leads to the awareness of the human being. Among the resources to be incorporated in this process, we highlight cinema as an instrument for the effectiveness of education through art and culture, because it favors (self) knowledge of feelings and allows critical reflection on reality. Therefore, the central objective is to develop a debate about the relationship between cinema use and the development of awareness in teacher education. We argue that in this direction, teacher education can contribute to overcoming forms of inculcation of dehumanizing ideologies and lead to the development of democracy in and through education. It is a bibliographical research, based on the qualitative approach of the data.
\end{abstract}

Keywords: Awareness. Art and Culture. Aesthetic and Ethical Training. Movie Theater. Teacher Training.

\section{INTRODUÇÃO}

A formação de professores para a educação básica no Brasil, nas últimas décadas, passou por substantivas reformulações. As políticas educacionais fundamentadas na legislação atual e nos documentos oficiais, quer seja em nível Nacional, Estadual e Municipal, em suas diferentes modalidades, têm nos levado progressivamente a um repensar sobre os cursos de formação e a prática docente, no que se refere à concepção, ao significado, à estrutura, às condições, ao público, ao lócus de formação docente, entre outros, pois, ao que parece, o modelo vigente não atende, por um lado, às necessidades formativas dos educadores $\mathrm{e}$, por outro, não satisfaz às exigências da sociedade em geral, resultando em frequentes 
discordâncias, críticas e reflexões em torno do contexto supracitado. (GATTI, 2010).

Ao discutir sobre os saberes docentes e a formação de professores, Nunes (2001) reconhece que pensar em um modelo de professor implica considerar a contextualização dos saberes docentes, bem como demanda observar as condições históricas e sociais de exercício profissional. $\mathrm{O}$ autor afirma que:

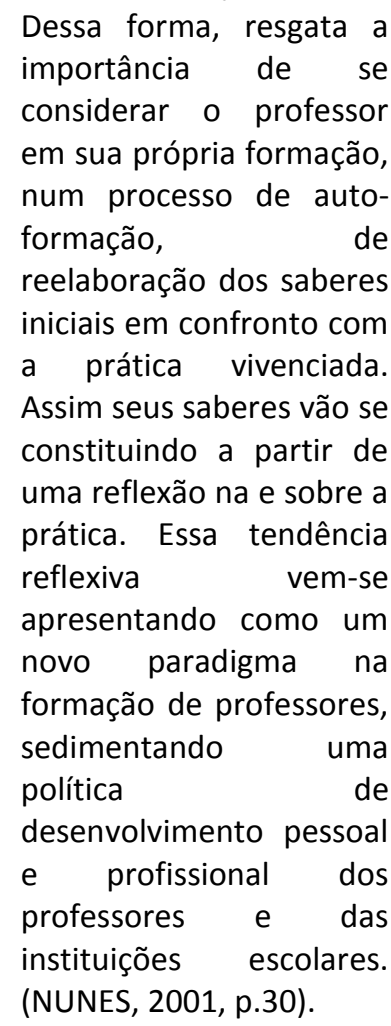

Em função dessas reflexões, principalmente a partir da década de 1990, pesquisadores, educadores, professores, alunos e os sistemas educacionais, têm buscado um novo enfoque para a formação de professores, identificando e analisando os saberes docentes numa perspectiva de contribuir para a ampliação do campo e para implementação de políticas que envolvam a questão de formação do professor (ASSIS, 2014).

Num sentido aproximado, recorremos a Read (2001) que, fundamentado em Platão (2001), defende o desenvolvimento da educação pela arte, ou seja, a arte deve ser uma das bases da educação. Nesse tocante, as reflexões em curso estão guiadas por essas asserções, que buscam a consolidação de um projeto educativo desenvolvido na direção da formação integral do professor, ou seja, que atenda às necessidades formativas desse profissional, possibilitando-lhe a evolução da (mera) habilitação profissional à formação para a Pedagogia da Autonomia, proposta por Freire (2002). Neste caso, a arte e a cultura são consideradas recursos formativos essenciais.

Nessa perspectiva, a arte na formação docente é compreendida como importante instrumento de conhecimento e autoconhecimento dos educadores e pode contribuir no projeto educativo, pois, segundo Read (2001), possui duas funções básicas: estimular as potencialidades (inatas) das pessoas e nelas instituir a cultura vigente da qual fazem parte. Nesse sentido, o desenvolvimento da educação estética se torna fundamental, destacando-se a educação dos sentimentos. Ou seja, entre suas funções, cabe à educação formar "artistas", "pessoas sensíveis e eficientes nos vários modos de expressão", evitando, contundo, o prejuízo da criticidade quanto ao contexto real, ao contrário, ter na sensibilidade um facilitador para a percepção/compreensão do mundo (READ, 2001, p. 12).

Diante do exposto, entendemos que seja de suma importância a ampliação dos recursos para a formação docente, numa perspectiva que atenda às necessidades formativas do perfil profissional ligado ao contexto histórico em que vive, considerando, dessa forma, os fatores que provocam impactos e constituem toda a sua formação humana e profissional.

Entre os fatores supramencionados, destacamos o impacto dos estímulos audiovisuais, que, ao que observamos, não apenas estimulam, mas educam a sociedade civil contemporânea. Por isso mesmo, compreendemos ser essencial a (re) organização dos currículos educacionais em articulação com a tecnologia em prol do desenvolvimento da consciência crítica, bem como do ser humano mais solidário.

Diante do exposto, notamos o quão se faz necessária a reflexão sobre os currículos dos cursos de licenciaturas, pois, em concordância com Gatti (2010), a problemática no cenário desses cursos é um assunto presente em constantes debates há tempos e mesmo após a exigência de formação em nível superior de professores, o cenário permanece carente de ações e de políticas de melhorias. Segundo a autora,

Hoje, em função dos graves problemas que enfrentamos no que respeita às aprendizagens escolares em nossa 
sociedade, a qual se complexifica a cada dia, avoluma-se a preocupação com as licenciaturas, seja quanto às estruturas institucionais que as abrigam, seja quanto aos seus currículos e conteúdos formativos. (GATTI, 2010, p. 1359).

Do mesmo modo, concebemos como imprescindível a reflexão sobre a formação docente na esfera contínua, pois, além da qualidade e necessidade de evolução constante do ser humano, ressaltamos a sua vocação ontológica de ser mais, que conforme esclarece Freire (2002), refere-se pela capacidade permanente de humanização das pessoas.

Na perspectiva da formação pela e para a Pedagogia da Autonomia, destacamos a relevância do cinema como conteúdo curricular constante nos cursos de licenciaturas e de formação contínua, uma vez que esse recurso pode possibilitar a ampliação do projeto educativo, ao promover o desenvolvimento da educação pela arte, pois, favorece o conhecimento e autoconhecimento dos sentimentos, bem como permite a reflexão crítica sobre a realidade.

Nessa direção, defendemos que a sua incorporação na ação pedagógica transcende ao uso restrito do cinema em sala de aula, ou seja, defendemos, por um lado, a utilização desse recurso como uma das formas de desenvolver a educação por meio da sensibilidade inerente à arte e à cultura e, por outro lado, refutamos a sua utilização de forma irrefletida.

Duarte (2002) adverte que,

Imersos numa cultura
que vê a produção
audiovisual r como
espetáculo de diversão, a
maioria dos professores
faz uso dos filmes apenas
como recurso didático de
segunda ordem, ou seja,
para ilustrar de forma
lúdica e atraente o saber
que acreditamos estar
contido em fontes mais
confiáveis (DUARTE,
2002, p.87).

Nesse sentido, cabe lembrar a reflexão de Freire (2002) quando destaca a ética e a estética como saberes necessários à prática educativa. Para o autor "divinizar ou diabolizar a tecnologia ou a ciência é uma forma altamente negativa e perigosa de pensar errado" (FREIRE, 2002, p. 37).

Nesta linha de pensamento novas provocações emergem em torno de como a utilização do cinema na formação docente contribui efetivamente para a formação de educadores críticos, reflexivos, emancipados intelectualmente, e que, paralelamente, assumam uma postura fundamentada na ética, no diálogo, ou seja, no compromisso histórico e cultural.

Diante do exposto, a problemática norteadora deste estudo consiste na seguinte questão: como a utilização do cinema pode contribuir para a formação docente de maneira que esses profissionais façam o uso desse recurso numa perspectiva da Pedagogia da Autonomia proposta por Paulo Freire?

Ademais, como os educadores percebem o uso cinema, enquanto conteúdo curricular, em sua formação acadêmica e profissional?

A hipótese inicial para a questãoproblema acima consiste na ideia de que o cinema pode contribuir para a formação de professores comprometidos com os princípios da Pedagogia da Autonomia quando a metodologia adotada no uso do recurso for fundamentada na práxis dialógica, o que requer a ampla reflexão e o diálogo efetivo, entre professor-formador e educadores em formação, sobre a função social desse mecanismo (o cinema) na referida formação.

Assim, este trabalho tem o objetivo central de provocar reflexões e discussões sobre o uso do cinema na formação docente com vistas ao desenvolvimento da ação pedagógica firmada na perspectiva da Pedagogia da Autonomia, que busca consolidar a conscientização de mundo do ser humano por meio da educação.

Vale destacar que, por Pedagogia da Autonomia definimos, aqui, como a ação pedagógica fundada nos princípios da evolução do pensamento ingênuo à consciência crítica, ou seja, a ação pedagógica pautada na conscientização e na ação formativa de conduzir a esse patamar do pensamento.

Quanto ao uso do cinema, defendemos que esse recurso midiático pode ser uma alternativa no processo de desenvolvimento da conscientização humana, que busca superar as 
formas de inculcação de ideologias alienantes e conduzir à democracia e à liberdade.

\section{O uso do cinema e o a formação docente: reflexões sobre 0 desenvolvimento da conscientização}

Ao abordarmos a temática em torno da relação entre o cinema e a formação docente para o desenvolvimento da Pedagogia da Autonomia, somos remetidos à abordagem de pelo menos duas questões importantes: a educação pela arte e cultura e a formação estética e ética do professor.

A educação pela arte e cultura, defendida por Read (2001), torna-se essencial na formação docente porque trata diretamente da sensibilidade humana. Está ligada à capacidade de abstração de homens e de mulheres e à interpretação dos fenômenos da realidade para além do que está explícito.

$\mathrm{Na}$ mesma direção, a sensibilidade referida acima está ligada à qualidade do ser humano de se relacionar com o mundo e com o contexto histórico-cultural de sua realidade. Sendo assim, a formação estética e ética pode ser considerada vital no desenvolvimento dessa relação homem-mundo-sociedade.

Nesse contexto, quando pensamos na formação docente por meio da arte e cultura, através do uso do cinema, reportamo-nos à formação estética e ética, consagrada nos pressupostos freireanos. O que nos leva a constatar que essa relação pode favorecer o desenvolvimento da conscientização de mundo, que é uma característica posta por Freire (2003) como indispensável à libertação de homens e de mulheres.

Sobre o conceito de conscientização que nos referimos, cabe retomarmos as definições de Freire (2003). Segundo o autor, é possível verificarmos pelo menos duas modalidades de consciência humana. A primeira é caracterizada pela centralidade dos interesses do homem em torno das formas mais primitivas e vegetativas de vida. Nessa posição, não há fundamentação histórico-cultural, e, portanto, se trata de pensamentos fundados numa consciência intransitiva". "É a consciência dos homens de zonas pouco ou nada desenvolvidas do país. São uns 'demitidos da vida' ou, talvez mais precisamente uns inadmitidos à vida [...]"

\footnotetext{
${ }^{1}$ Estão grafados em itálico os termos ligados a conceitos específicos de autores.
}

(FREIRE, 2003, p. 32). Na segunda modalidade, Freire (2003) anuncia a consciência transitiva, que corresponde aos interesses daqueles pertencentes às situações econômicas mais desenvolvidas. Seus interesses são movidos por perspectivas mais amplas, distintos dos interesses vegetativos. As preocupações que motivam essa posição da consciência são fortemente marcadas pela espiritualidade e historicidade (FREIRE, 2003).

Freire (2003) ainda alerta que a modalidade transitiva pode ser caracterizada por dois estágios, sendo que, num primeiro momento se configura predominantemente ingênuo, podendo ser identificado pela simplicidade na interpretação de problemas, por outro lado, num estágio mais avançado, podemos caracterizar a transitividade crítica da consciência, identificada pela profundidade na interpretação dos problemas.

O mesmo autor ainda esclarece que a consciência marcada pela intransitividade representa quase um incompromisso do homem com a sua existência e por isso a relação dele com a realidade é comparada a um estágio vegetativo. "Escapa ao homem intransitivamente consciente a apreensão de problemas que se situam além de sua estreita esfera biologicamente vital" (FREIRE, 2003, p. 34).

Entretanto, Freire (2003) elucida que o conceito de intransitividade não significa um fechamento do homem dentro dele mesmo, como se não fosse capaz de evoluir. Qualquer que seja o estágio de seu pensamento, o homem sempre é um ser aberto, ontologicamente aberto, com vocação para evoluir. O que tenta salientar é a limitação da capacidade de apreensão própria da intransitividade da consciência. "É a sua inaudição a estímulos situados fora da órbita vegetativa" (FREIRE, 2003, p. 35). É neste sentido que a sua intransitividade representa quase um incompromisso com a sua existência.

Diante dessas questões, é importante pensarmos na evolução da consciência. Sobre isso, Freire (2003) explica que a promoção da consciência intransitiva para a posição transitivoingênua acontece de maneira automática, à medida que ocorre a promoção dos padrões econômicos da comunidade. Isso significa que, conforme é lançado a formas de vida mais complexas, conforme as suas relações vão se ampliando e passando a receber maior número de sugestões de suas circunstâncias, a transitividade da consciência humana vai se 
estabelecendo e evoluindo cada vez mais. Por outro lado, a evolução da consciência predominantemente transitivo-ingênua para a consciência crítica não ocorre espontaneamente, mas, requer um trabalho educativo com essa destinação (FREIRE, 2003).

É nesse estágio da evolução da consciência, a transitividade crítica, que defendemos como o grande desafio a ser assumido pela educação. Pois, se para chegar a esse patamar da consciência é necessária a intervenção educativa, do outro lado, a não evolução da posição ingênua consolida as formas mais desumanizantes na relação homemmundo-sociedade, já que levam o homem a posições mágicas e míticas, comprometendo a mentalidade democrática (FREIRE, 2003).

Freire (1987) salienta que, em oposição à sectarização materializada no cenário da contradição opressor/oprimido, a conscientização leva homens e mulheres ao (re) conhecimento do mundo, do seu lugar no mundo e a assumir posições de resistência e luta em favor da justiça social. Além disso, o mesmo autor adverte que "precisamos estar convencidos de que o convencimento dos oprimidos de que devem lutar por sua libertação não é doação que Ihes faça a liderança revolucionária, mas resultado de sua conscientização" (FREIRE, 1987, p.30).

Ainda em Freire (1987),

Por tudo isto é que defendemos o processo revolucionário como ação cultural dialógica que se prolongue em "revolução cultural" com a chegada ao poder. $E$, em ambas, o esforço sério e profundo da conscientização, com que os homens, através de uma práxis verdadeira, superam o estado de objetos, como dominados, e assumem o de sujeito da História (FREIRE, 1987, p. 91).

Nessa perspectiva, o projeto educativo escolar deve ser organizado e desenvolvido na esteira de uma metodologia dialógica, com vistas à conscientização de mundo. Na prática, isso significa que a educação escolar tem a função essencial de conduzir a sua comunidade ao permanente diálogo, com a sua existência e com as circunstâncias específicas, sendo refutadas as atividades escolares fundadas em formas semelhantes à produção em massa, com práticas de domesticação e com base em conteúdos e procedimentos padronizados (BEISIEGEL, 2008, p. 128).

O professor, enquanto figura política e pedagógica, dotada de alto grau de diretividade, tem em suas mãos uma dose massiva de responsabilidade quanto ao desenvolvimento da conscientização de seus alunos. Por isso, pensar numa formação estética e ética dos professores, que esteja a serviço da liberdade e da democracia se torna um princípio fundamental da ideia e da prática da formação global, enquanto direito humano universal.

Nessa perspectiva, a cinematografia possui a potencialidade - dentre tantas outras de educar, mas não o apenas no que se refere ao uso do objeto, sobretudo, quanto à reflexão crítica desse contexto educativo, o que requer a mediação e a construção do diálogo entre o objeto (cinema), o mediador (professorformador) e os educadores em formação.

Nesse contexto, faz-se necessária a "alfabetização" crítica dos elementos que estão a nossa volta, em nosso cotidiano, que, por vezes, passam despercebidos aos "nossos olhos", resultando na naturalização de ideias prontas, ideologias doutrinadoras e concepções fundamentadas no senso comum, o que vem consolidando (com forte contribuição da mídia), décadas após décadas, as formas desumanizantes de educação, que se mantém a serviço da contradição opressor/oprimido.

A despeito disso, Freire (2002) enfatiza sobre os riscos da naturalização das informações e demais elementos midiáticos, bem como da suposta neutralidade dos recursos tecnológicos e ausência de reflexões sobre as intencionalidades políticas e ideológicas implícitas nos elementos propagados pelos meios de comunicação.

Para o autor,

[...] pensar em televisão ou na mídia em geral nos põe o problema da comunicação, processo impossível de ser neutro. $\mathrm{Na}$ verdade, toda a comunicação é comunicação de algo, feita de certa maneira em favor ou na defesa, sutil ou explícita, de algum 
ideal contra algo e contra alguém, nem sempre claramente referido. (FREIRE, 2002, p. 139).

Contudo, destacamos uma declaração de Freire (2002) que expressa a justificativa deste debate: "o sujeito que se abre ao mundo e aos outros inaugura com o seu gesto a relação dialógica em que se confirma como inquietação e curiosidade, como inconclusão em permanente movimento na História". (FREIRE, 2002, p. 136).

\section{METODOLOGIA}

A metodologia adotada neste estudo se fundamenta em uma perspectiva qualitativa. Isto porque esse tipo de abordagem permite 0 tratamento interpretativo dos dados coletados para além da quantificação, o que contribui tanto para a apresentação analítica dos mesmos como para o debate sobre as melhorias possíveis no cenário em questão.

Para Rey (1998, p.42) "a investigação qualitativa substitui a resposta pela construção, a verificação pela elaboração e a neutralidade pela participação". Ou seja, o percurso metodológico não se encerra após a coleta das informações, mas, passa por um profundo processo de leitura, interpretação e diálogo com dados, possibilitando o confronto entre o problema propulsor do estudo e as informações levantadas, num processo onde vão emergindo, por um lado, novas questões e, por outro, as respostas almejadas.

No caso deste estudo, a coleta de dados se deu por meio de uma pesquisa bibliográfica, com a seleção e o estudo das obras que abordam a questão principal aqui apresentada. Após o levantando das informações e análises das abordagens dos autores, as constatações foram emergindo.

Cabe salientar que o debate proposto requer aprofundamento teórico e empírico e, nesse sentido, justificamos a apresentação deste trabalho nos espaços acadêmicos, pois, acreditamos que as discussões podem ser significativas para a ampliação e o fortalecimento do estudo em tela.

\section{REFLEXÕES E CONSIDERAÇÕES FINAIS}

Este estudo lança questões-problema que não são novas no campo educacional, mas que permanecem como sintomas das lacunas inviabilizadoras da formação global, consagrada como direito humano universal nas mais diversas legislações educacionais e nas publicações de autores dessa área.

No percurso de análise dos dados, pautados nas ideias dos autores referenciados, foram apresentadas neste texto algumas dimensões da educação e, de outro lado, foram defendidos alguns princípios fundamentais que caminham na direção da liberdade humana. Sobre essas dimensões, colocamos a formação docente como importante condutor ao caminho da educação que se quer voltada aos princípios da democracia, da autonomia de pensamento de mulheres, homens, educadores. Notamos que, anos após anos de estudos sobre a formação docente, ainda carecemos da efetivação de uma formação profissional que conduza educadores à evolução quanto aos saberes necessários à prática educativa.

Isso significa que os estudos de Paulo Freire sobre a "Pedagogia da Autonomia" continuam contribuindo para o debate acerca da necessária (re)construção da educação como instância propulsora da evolução do pensamento ingênuo à consciência crítica. Nessa visão, os espaços de formação docente precisam atender essa necessidade formativa, conduzindo para o sentido do desenvolvimento da conscientização.

Sabemos que existe uma gama de possibilidades voltadas à formação humana e, por conseguinte, à formação de professores, que são pessoas antes de tudo. Por isso, decidimos delimitar uma dimensão que contemplasse ao mesmo tempo a capacidade de racionalização da pessoa humana e a sua qualidade de ser sensorial.

Nesse ponto da reflexão, emergiram os eixos temáticos educação pela arte e cultura e a formação estética e ética dos professores. Salientamos a educação pela arte e cultura no campo da formação docente porque está diretamente ligada ao desenvolvimento da sensibilidade humana e pode potencializar a capacidade de abstração e de interpretação de fenômenos da realidade. Do mesmo modo, a formação estética e ética se articula com a qualidade sensitiva do ser humano, mas, ainda, pode potencializar as formas de relação da pessoa com o mundo e com o seu contexto histórico-cultural, sendo assim, é considerada vital no desenvolvimento da relação homemmundo-sociedade.

Diante do exposto, entendemos que seja de suma importância para a formação docente a 
incorporação de recursos ligados, concomitantemente, à ampliação da capacidade de interpretação do contexto histórico-cultural e social e a exploração da qualidade sensitiva de educadores/humanos.

Dentro dessa perspectiva, sabemos que diversos fatores provocam impactos e, até mesmo, constituem a formação humana e profissional, entre eles, destacamos os estímulos audiovisuais, que, ao que se observa, não apenas estimulam, mas educam a sociedade civil contemporânea. Nessa perspectiva, a cinematografia possui a potencialidade - dentre tantas outras - de educar e pode ser utilizada a serviço da reflexão crítica da realidade, numa perspectiva macro de formação, bem como viabilizar o diálogo e a identificação das necessidades formativas específicas no que se refere aos saberes necessários à prática educativa.

Por isso, compreendemos ser essencial a (re) organização dos currículos educacionais articulados com a tecnologia em prol do desenvolvimento da consciência crítica. Nessa direção, a incorporação do uso do cinema na ação pedagógica transcende ao uso restrito e irrefletido em sala de aula. Isso significa que, no campo da formação docente, o uso do cinema (e de demais recursos midiáticos) precisa, por meio da práxis dialógica, contribuir para formação de profissionais criticamente capazes de colocarem esses recursos a serviço da formação de seres humanos socialmente ativos e mais solidários uns com os outros.

Sobretudo, reconhecemos e reafirmamos a importância da formação docente, inicial e contínua, pautada na perspectiva de conscientização de Paulo Freire como possibilidade de construção da autonomia docente e a oportunidade de desenvolvimento de práticas educativas libertadoras.

\section{REFERÊNCIAS}

ASSIS, T. P. Formação contínua em serviço: o olhar do professor. 2014. 199 f. Dissertação (Mestrado em Educação) - Faculdade de Ciências e Tecnologia, Universidade Estadual Paulista, Presidente Prudente, 2014.

BEISIEGEL, C. R. Política e educação popular: a teoria e a prática de Paulo Freire no Brasil. 4. ed. Brasília: Liber Livro, 2008.
DUARTE, R. Cinema \& educação. Belo Horizonte: Autêntica, 2002.

FREIRE, P. Educação e atualidade brasileira. 3 ed. São Paulo: Cortez; Instituto Paulo Freire, 2003.

FREIRE, P. Pedagogia da autonomia: saberes necessários à prática educativa. São Paulo: Paz e Terra, 2002.

FREIRE, P. Pedagogia do oprimido. 17. ed. Rio de Janeiro: Paze Terra, 1987.

GATTI, B. A. Formação de professores no Brasil: características e problemas. Educação \& Sociedade, Campinas, v. 31 , n. 113, p. 1355-1379, out./dez. $2010 . \quad$ DOI https://doi.org/10.1590/S0101733020100004000 $\underline{16}$

NUNES, C. M. F. Saberes docentes e formação de professores: um breve panorama da pesquisa brasileira. Educação \& Sociedade, Campinas, n. 74, p. 27-42, abr. 2001.

PLATÃO. A república. São Paulo: Martin Claret, 2001.

READ, Herbert. A educação pela arte. São Paulo: Martins Fontes, 2001.

REY, F. Lo cualitativo y lo cuantitativo en la investigación de la psicología social. Psicologia \& Sociedade, São Paulo, v. 10, n. 2, p. 32-52, 1998.

Recebido para publicação em: 02/10/2017

Revisado em: 06/11/2017

Aceito em: 13/12/2017 